11. Kreuger, J., Prydz, K., Pettersson, R.F., Lindahl, U. \& Salmivirta, M. Characterization of fibroblast growth factor 1 binding heparan sulfate domain. Glycobiology $\mathbf{9}$ 723-729 (1999)

12. Venkataraman, G., Shriver, Z., Raman, R. \& Sasisekharan, R. Sequencing complex polysaccharides. Science 286, 537-542 (1999).

13. Rhomberg, A.J., Ernst, S., Sasisekharan, R. \& Biemann, K. Mass spectrometric and capillary electrophoretic investigation of the enzymatic degradation of heparin-like glycosaminoglycans. Proc. Natl. Acad. Sci. USA 95, 4176-4181 (1998).

14. Faham, S., Hileman, R.E., Fromm, J.R., Linhardt, RJ. \& Rees, D.C. Heparin structure and interactions with basic fibroblast growth factor. Science 271, 1116-1120 (1996).

15. DiGabriele, A.D. et al. Structure of a heparin-linked biologically active dimer of fibroblast growth factor. Nature 393, 812-817 (1998).

16. Faham, S., Linhardt, R.J. \& Rees, D.C. Diversity does make a difference: Fibroblast growth factor-heparin interactions. Curr. Opin. Struct. Biol. 8, 578-586 (1998).

17. Jin, L. et al. The anticoagulant activation of antithrombin by heparin. Proc. Natl. Acad. Sci. USA 94, 14683-14688 (1997).
18. Fry, E.E. et al. The structure and function of a foot-and-mouth disease virus-oligosaccharide receptor complex. EM BO J. 18, 543-554 (1999).

19. Pervin, A., Gallo, C., Jandik, K.A., Han, X.J. \& Linhardt, RJ. Preparation and structural characterization of large heparin-derived oligosaccharides. Glycobiology 5, 83-95 (1995).

20. Sperinde, G.V. \& Nugent, M.A. Heparan sulfate proteoglycans control intracellular processing of bFGF in vascular smooth muscle cells. Biochemistry 37, 13153-13164 (1998).

21. Padera, R., Venkataraman, G., Berry, D., Godavarti, R. \& Sasisekharan, R. FGF-2/fibroblast growth factor receptor/heparin-like glycosaminoglycan interactions: A compensation model for FGF-2 signaling. FASEB J. 13, 1677-1687 (1999).

22. Wang, H., Tseng, K. \& Lebrilla, C.B. A general method for producing bioaffinity MALDI probes. Anal. Chem. 71, 2014-2020 (1999).

23. Brickman, Y.G. et al. Structural comparison of fibroblast growth factor-specific heparan sulfates derived from a growing or differentiating neuroepithelial cell line. Glycobiology 8, 463-471(1998).

\title{
ON THE MARKET
}

\section{THERM AL CYCLERS}

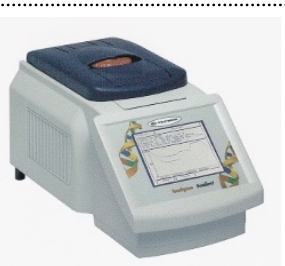

Touchgene gradient thermal cycler.

Optimize experiments at the touch of a screen, says Techne, using its Touchgene gradient thermal cycler. The device offers a gradient range of $30^{\circ} \mathrm{C}$ and 'Quad' circuit technology, where four independent temperature sensors control eight peltier units. The graphical display shows the sampletemperature profile in real time while the program is running, including the upper and lower temperature limits of the gradient. Special gradient features that enable usersto replicate experimental conditions include a gradient cal culator function that displays the actual temperature of each column, and active ramping and fourfold control that ensures that each sample is at the target temperature for the same hold time. Other design features include multiple interchangeable block formats, memory cards and a maximum ramp rate of greater than $3^{\circ} \mathrm{C} / \mathrm{s}$.

Tel. (+44) (0) 1223-832401

Fax $(+44)(0)$ 1223-836838

www.techneuk.co.uk

\section{ONLINE SHOPPING}

Biosupplies, a provider of e-commerce solutions for the life sciences, has launched PurePeptides. PurePeptides is an Internet-based tool that provides researchers with a convenient way to order peptides. The service enables users to build a peptide or protein onlineand sel ect from an extensive range of modifications and options. PurePeptides then enables the user to view a list of potential manufacturers, check their prices and order the product online. PurePeptides complements the company's launch of PureDNA.

Tel. (+1) 215-387-1689

Fax (+1) 215-895-3101

Website: www.biosupplies.com

SIM PLIFYIN G SEQUEN CING SETUP

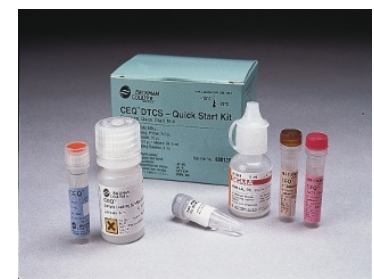

Beckman's new kit simplfies reaction setup for DNA sequencing.

Beckman Coulter's new kit - the CEQ DTCSQuick Start Kit - simplifies dyeterminator cycle sequencing reaction setup. The kit features a master mix of components that reduces the required number of pipetting steps from ten to four, producing significant time savings, according to the company. At the same time, the kit uses larger transfer volumes to reduce pipetting errors. The kit is designed to work with the CEQ 2000XL DNA sequencing system. For complete automation of reaction setup, the kit can be used with theBiomek FX and Biomek 2000 automated liquid handling systems, al so from Beckman Coulter.

Tel. (+1) 714-871-4848

Fax (+1) 714-773-6611

www.beckmancoulter.com

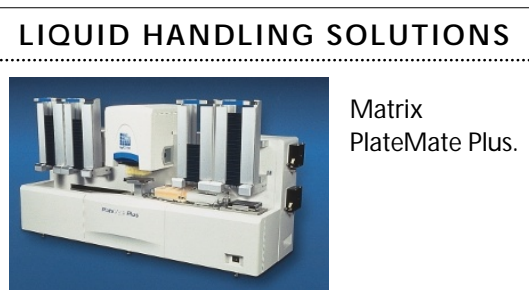

Matrix Technologies has introduced the PlateM ate Plus, a high-thoughput system with interchangeable pipetting heads. Each platform offers the ability to work with 96-, 384- and/or 1,536-well plates using either a 96- or 384-tip configured head for liquid processing. In addition to precise reagent addition, mother/daughter plate replication and plate pooling applications, the PlateM ate Plus can also accomplish serial dilutions and microplate reformatting between 96-, 384- and 1,536-well plates. Available with removable front-loading universal stackers and ControlMate Windowsbased software.

\section{Tel (+1) 800-345-0206}

www.matrixtechcorp.com

\section{NOT A CASE OF 'ALL HANDS TO} THE PUMP'

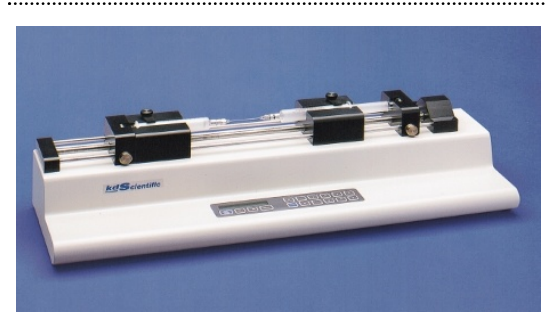

HandSaver microemulsion device takes the effort out of mixing adjuvant antigen emulsions.

The HandSaver microemulsion pump from Stoelting automates the laboratory task of mixing adjuvant/antigen emulsions by forcing the fluid back and forth through a double-hub needle. With the HandSaver device, simply mount the syringes on the pump and return when thorough emulsions are achieved, says the company.

Tel. (+1) 630-860-9700

Fax (+1) 630-860-9775

www.stoeltingco.com 